\title{
The Epistemology of Disagreement
}

\author{
Bryan Frances \\ University of Tartu \\ Tartu, Estonia \\ Bryan.frances@yahoo.com
}

\section{Introduction}

As this entry is written, in July 2019, a good portion of the philosophical community is embroiled in vociferous disagreement about how, if at all, certain controversial views about gender identity should be discussed, especially regarding the identities of trans people. There are many participants who are extremely confident that philosophers who defend certain of the controversial views should be censured and prevented from advancing those positions at professional conferences and in scholarly journals, on the grounds that significant harm will occur virtually no matter how the discourse goes. Many others are extremely confident that that idea is just plain false. Furthermore, it is quite common for people on both sides of the issue to think many if not most of the people on the other side are one or more of: culpably clueless, evil, culpably careless, or in the grip of irrationality.

That is an example of a relatively recent public disagreement. Others are far older. For instance, how can one have an epistemically reasonable religious belief, pro or con, given that one knows full well that it's highly controversial even amongst people who are extremely intelligent and have investigated the relevant issues for many years? The religious belief might be something relatively specific, such as "Muhammad spoke with an angel" or "The soul is reincarnated." It might be something more fundamental, such as "God exists." It could be something scientific such as "There is an afterlife for humans." It could also be opposing beliefs: "Jesus is not the only means of salvation" or "God doesn't exist in any sense." In some cases, apparent disagreement is merely apparent. For instance, so-called disagreements about "salvation" are occasionally artifacts of different understandings of that term; so both of the "opposing" beliefs could well be true. But it's clear that in an enormous number of cases only one group can be right: Jesus either rose from the dead or he didn't, and we either are or are not conscious after the death of our bodies. If you 
believe $\mathrm{X}$ is true and they think $\mathrm{X}$ is false, then you're definitely saying that they are wrong and you are right.

It's clear that a great many people are utterly reasonable in sticking to their beliefs in the face of disagreement—in one familiar epistemic sense of "reasonable." For instance, a child with religious, political, or moral belief B might be told by her parents and all the other people she looks up to that although there are people who doubt or even reject B, they are screwed up in any of various ways: horribly irrational, biased, brainwashed, ignorant, insane, etc. She believes them on this score: why on earth would she not do so given that she is sheltered from reality, she has always unreflectively trusted those adults, and those adults have proven reliable about so many issues before? Nothing relevant changes if the believer is a sheltered adult instead of a child.

However, what about the philosophically challenging cases: a person isn't clueless about the fact that a great many of the people who disagree with her are intelligent, careful reasoners who are no more biased or ignorant than she is?

\section{Preliminaries: Belief, Action, Confidence, and Key Questions ${ }^{1}$}

There are just three stances to adopt regarding the truth of a claim: believe it's true, believe it's false (i.e., disbelieve it), and suspend judgment on it. Two individuals disagree about a proposition when they adopt different stances toward the same claim (i.e., one believes it and the other disbelieves it, or one believes or disbelieves it and the other suspends judgment). But there is a range of levels of confidence one can have regarding a claim as well. We may agree that global warming is catastrophic but you may be much more confident than I am. For the sake of simplicity this entry will ignore levels of confidence. It will also focus on disagreements where there is a fact of the matter, or at least the participants are reasonable in believing that there is such a fact. Finally, note that when it comes to disagreements over what to do, instead of what to believe, there are not three options but just two: do X, don't do X. We will focus on disagreements over beliefs.

There are two key questions to ask about the epistemology of disagreement. The first:

\footnotetext{
${ }^{1}$ Much of sections 2-4 is based on Frances and Matheson 2018
} 
Response Question: Suppose one realizes that some people disagree with her belief B. How must she respond to the realization in order for her response to be epistemically rational?

In most circumstances, in order to answer the Response Question one must first know the relative epistemic positions of the people one disagrees with. Very roughly, if one knows that they are clearly in a significantly better position to judge the issue under consideration, then in most cases one should give up one's belief that is the focus of dispute. If one knows that they are clearly in a significantly worse position to judge the issue, then in most cases one need not give up the contested belief. When one thinks it's a tie, or one has no idea as to their position compared to one's own, then matters are more complicated. The second key question:

Epistemic Position Question: Are the people who disagree with B in a better epistemic position to correctly judge the truth-value of B than the people who agree with B? Or a worse position? Or roughly equal? Or is one quite uncertain about it?

Depending on how one understands 'belief', the Response Question can be either difficult or easy to answer, for the following reasons.

Sometimes when one is asked what her view is on a subject, she will respond by expressing her overall view on the matter. It's all cut and dry: is Terrance married or not? But when it comes to a controversial subject, say the issue of whether we have free will, we sometimes respond in a different way, by giving what can be called our restricted view. For instance, when Jo states her pro-free will view all she is doing is saying that when she weighs the pros and cons on her own, going by her own lights alone, she feels as though the pros are winning, even though she ultimately thinks the evidence she knows about doesn't really warrant having any certain view on the matter. She is offering a restricted reaction to the pro and con considerations: "Here is the direction in which I find myself moved when I weigh the evidence myself, ignoring what anyone else has to say on the matter and ignoring the likely fact that I have only a small part of the relevant evidence." This interpretation is bolstered by the fact that many people will be unperturbed that others disagree with them. For instance, if Bo said to Jo, "Well, I think free will is an illusion," Jo may well not be bothered at all. It's not that she thinks there is no truth of the matter. Instead, she thinks that (a) no one really knows the answer, and (b) because no one really knows, all we can do is express how the issue strikes us, how we judge it when going by our own lights. It's not terribly different from expressing one's preference for chocolate over vanilla. 
Disagreement becomes a challenge only when considering the first, "overall view" notion of belief and setting aside the restricted one.

\section{Epistemic Peers, Inferiors, and Superiors}

One can make judgments about how likely someone is to correctly answer 'Is belief B true?' If Jo thinks Bo is more likely (e.g., Jo supposes that the odds that she will answer it correctly are about $90 \%$ whereas Bo's odds are just around 80\%), then Jo thinks she is Bo's epistemic superior on that question; if she thinks she is less likely, then she thinks she is Bo's epistemic inferior on that question; if she thinks she is about equally likely, then she thinks she is Bo's epistemic peer on that question. Another way to describe these distinctions is by referencing the epistemic position of the various parties. One's epistemic position describes how well-placed they are, epistemically speaking, with respect to a given belief. The better one's epistemic position, the more likely one is to be correct.

There are many factors that help determine one's epistemic position, or how likely one is to correctly answer 'Is belief B true?' Here are the main ones (Frances 2014):

- cognitive ability had while answering the question

- evidence brought to bear in answering the question

- relevant background knowledge

- time devoted to answering the question

- distractions encountered in answering the question

- relevant biases

- attentiveness when answering the question

- intellectual virtues possessed

Call these Disagreement Factors. Presumably, what determines that $\mathrm{X}$ is more likely than $\mathrm{Y}$ to answer 'Is B true?' correctly are the differences in the Disagreement Factors for $\mathrm{X}$ and $\mathrm{Y}$.

One can come out on top in many different ways. For instance, in a case of one-on-one disagreement, Jo knows full well that the person who disagrees with her is generally smarter than she is, in terms of intellectual ability. But she also knows that he is woefully uninformed compared to herself. Or maybe she knows that his opinion is based on a strong, unjustified bias whereas she is suffering from no such problem. 
In those cases, she can be reasonable in sticking with her opinion even though she admits that he surpasses her on some Disagreement Factors.

For any given case of disagreement between just two people, the odds are that they will not be equivalent on all Disagreement Factors: $\mathrm{X}$ will surpass $\mathrm{Y}$ on some factors and $\mathrm{Y}$ will surpass $\mathrm{X}$ on other factors. If Jo is convinced that Bo is clearly lacking compared to her on many Disagreement Factors when it comes to answering the question 'Is B true?' then she will probably say that she is more likely than Bo is to answer the question correctly provided she is not lacking compared to him on other Disagreement Factors. If she is convinced that Bo definitely surpasses her on many Disagreement Factors when it comes to answering 'Is B true?' then she will probably say that she is less likely than he is to answer the question correctly provided she has no advantage over him it comes to answering 'Is B true?'. If she thinks the two of them differ in Disagreement Factors but the differences do not add up to one person having a net advantage (so she thinks any differences cancel out), then she will think they are peers on that question.

The Epistemic Position Question is often difficult to answer. For the majority of cases of disagreement, with $\mathrm{X}$ realizing she disagrees with $\mathrm{Y}, \mathrm{X}$ will not have much evidence to think $\mathrm{Y}$ is her peer, superior, or inferior when it comes to correctly judging B. For instance, if Jo is discussing with her neighbor Bo whether their property taxes will be increasing next year, and she discovers that she disagrees with Bo, she may have very little idea how the two of them measure up on the Disagreement Factors. She may know that she has more raw intelligence than he has, but she probably has no idea how much he knows about local politics, how much he has thought about the issue before, etc. She will have little basis for thinking she is his superior, inferior, or peer. These are the unknown cases. Thus, when one discovers that one disagrees with someone over B, one need not think, or have reason to think, that she is one's peer, superior, or inferior when it comes to judging B.

\section{Disagreements and Numbers}

Many disagreements are one-on-one: one person disagrees with another person and as far as they know they are the only two who have any opinion on the matter. Lisa thinks that she and Marie should move in together; then Lisa discovers that Marie has the opposite opinion. Many other disagreements involve just a few people. Bob, Rob, Hob, and Gob work in a small hotel and are wondering whether to ask for raises in their hourly pay rate. After discussion Bob thinks they should, Rob and Hob think they shouldn't, and Gob is undecided. When Bob learns all this about his three colleagues, what should his doxastic reaction be to this mixed bag of agreement and disagreement? 
When it comes to many beliefs, including some of the most interesting ones, one is fully aware that millions of people disagree and millions of other people agree. Just consider a belief about religionjust about any belief at all, pro or con. One is usually perfectly aware that the belief are controversial. Moreover, when it comes to controversial beliefs that large numbers of people have taken positions on, it's often the case that there are experts on the matter—one's epistemic superiors.

\section{Answering the Response Question}

At first glance, it seems that the right answer to the Response Question has three parts:

(a) If one has good overall reason to think one or one's group has the superior epistemic position to judge $B$, then retaining belief $B$ with no significant lowering of confidence level is rational.

(b) If one has good overall reason to think the other group has the superior epistemic position to judge $\mathrm{B}$, then retaining belief $\mathrm{B}$ with no significant lowering of confidence level is not rational.

(c) If one has good overall reason that the two groups are roughly equal in epistemic position, then retaining belief $\mathrm{B}$ with no significant lowering of confidence level is not rational.

Clauses (a) and (b) are plausible. Most of the literature concerns (c), with good reasons both pro and con.

Start with the pro reasons. Suppose Jo has a many-on-many disagreement over belief B. She has admitted that the opposing group is just as likely as hers to get the right answer on B's truth or falsity. Why on Earth would she think her group is right and they are wrong? After all, she just admitted that her group is just as likely to judge B correctly. But if she admits that, then she has to admit that her group has no advantage whatsoever in judging B. So, she should suspend judgment.

Think about what neutral party Pam would say if asked which group is right about B. Pam is like Jo in thinking that the two groups are equally likely to judge B correctly. By saying that the two groups are equally to have judged B correctly, Pam has nothing to point to in order to justify saying that Jo's group is the one that answered 'Is B true?' correctly; neither is there anything she can point to in order to justify thinking that the other group is right. So, Pam should suspend judgement because she admits the groups are peers. Since Jo admits the same thing Pam does, she should suspend judgment as well. 
The Equal Weight View endorses the above reasoning, saying that when one admits the two groups are peers with respect to $\mathrm{B}$, one acquires a reason to think one is wrong that is strong enough that one would be irrational to stick with fully believing B (cf. Bogardus 2009, Christensen 2007, Elga 2007, Feldman 2006, Frances and Matheson 2018, Matheson 2015a, and Matheson 2015b).

Advocates of the opposing position, the Steadfast View, have good objections to the Equal Weight View (cf. van Inwagen 1996, Kelly 2005, Plantinga 2000, Matheson 2015b, Frances and Matheson 2018). To understand one of them, consider a story.

Pat thinks B: little boys are just naturally more violent than little girls. He believes B because he is father of two boys and two girls and he has run a daycare for little kids for twenty-five years. Suppose further that he knows B is true, based on his first-hand experiences. By 'know' we mean something particularly strong. It's not mere true belief, as one can have a true belief that isn't knowledge (e.g., it's a random guess). Neither is knowledge merely a belief that is backed up by strong overall evidence, as one can have such a belief that fails to amount to knowledge (e.g., the evidence says Jones committed the crime, but it was his unknown identical twin). Roughly put, knowledge means getting it right—so the belief is true —and doing so for the right reasons.

Assume that the experts on child behavior have for a long time been stubbornly divided on the question of whether little boys are naturally more violent than little girls. They are well aware of the observational evidence that has suggested that boys are naturally more violent - they know all about the kinds of evidence Pat has - but for a decade now they have had studies that collectively strongly suggest the exact opposite. Pat is aware that the two groups of experts are about evenly divided and equally likely to have arrived at the truth on this issue.

Philosophers who reject the Equal Weight View often think that Pat's retaining his belief be rational given that he started out knowing B. The epistemic sin involved in retaining B-if it is such-is not so bad as to make his belief retention irrational.

\section{References}

Bogardus, Tomas. 2009. A vindication of the equal weight view. Episteme: A Journal of Social Epistemology 6 (3): 324-335. 
Christensen, David. 2007. Epistemology of disagreement: The good news. Philosophical Review 116: 187218.

Elga, Adam. 2007. Reflection and disagreement. Noûs 41: 478-502.

Feldman, Richard. 2006. Epistemological puzzles about disagreement. In Epistemic futures, ed. Steve Hetherington, 216-236. New York: Oxford University Press.

Frances, Bryan. 2014. Disagreement. Cambridge. UK: Polity Press.

Frances, Bryan. 2018. Scepticism and disagreement. In Skepticism: From antiquity to the present, eds. Diego Machuca and Baron Reed, 581-591. New York: Bloomsbury.

Frances, Bryan and Jonathan Matheson. 2018. Disagreement. In Stanford Encyclopedia of Philosophy, ed. Edward Zalta, Spring 2018 edn. <https://plato.stanford.edu/archives/spr2018/entries/disagreement/>

Matheson, Jonathan. 2015a. Disagreement and the ethics of belief. In The future of social epistemology: A Collective Vision, ed. James Collier, 139-148. Lanham, Maryland: Rowman and Littlefield.

Matheson, Jonathan. 2015b. The epistemic significance of disagreement. London: Palgrave Macmillan.

Plantinga, Alvin. 2000. Warranted Christian belief. Oxford: Oxford University Press. 